\title{
Adoption of pleurectomy and decortication for malignant mesothelioma leads to similar survival as extrapleural pneumonectomy
}

\author{
Hasan Fevzi Batirel, MD, PhD, ${ }^{a}$ Muzaffer Metintas, MD, ${ }^{\mathrm{b}}$ Hale Basak Caglar, MD, ${ }^{\mathrm{c}}$ Guntulu Ak, MD, \\ Perran Fulden Yumuk, MD, ${ }^{\mathrm{d}}$ Bedrettin Yildizeli, MD, ${ }^{\mathrm{a}}$ and Mustafa Yuksel, MD
}

\begin{abstract}
Objective: We changed our surgical approach to malignant pleural mesothelioma (MPM) in August 2011 and adopted pleurectomy and decortication (PD) instead of extrapleural pneumonectomy (EPP). In this study, we analyzed our perioperative and survival results during the 2 periods.

Methods: All patients who underwent surgical intervention for MPM during 2003-2014 were included. Data were retrospectively analyzed from a prospective database. Before August 2011, patients underwent evaluation for EPP and adjuvant chemoradiation (group 1). After August 2011, patients were evaluated for PD and adjuvant chemotherapy and/or radiation (group 2). Demographic characteristics, surgical technique, histology, side, completeness of resection, and types of treatments were recorded. Statistics was performed using Student $t$ test, $\chi^{2}$ tests, uni- and multivariate regression, and Kaplan-Meier survival analysis.
\end{abstract}

Results: The same surgical team operated on 130 patients. Median age was 55.7 years (range, 26-80 years) and 76 were men. EPP and extended PD was performed in 72 patients. Ninety-day mortality was $10 \%$. Median survival was 17.8 months with a 5-year survival rate of $14 \%$. Uni- and multivariate analyses showed that epithelioid histology, stage N0, and trimodality treatment were associated with better survival $(P=.039, P=.012$, and $P<.001$, respectively). Demographic variables and overall survival (15.6 vs 19.6 months, respectively) were similar between the groups, whereas nonepithelioid histology, use of preoperative chemotherapy, and incomplete resections were more frequent in group 2 ( $P<.001, P<.001$, and $P=.006$, respectively). Follow-up was shorter in group $2(22.5 \pm 20.6$ vs $16.4 \pm 10.9$ months; $P<.001)$.

Conclusions: Adoption of PD as the main surgical approach is not associated with survival disadvantage in the surgical treatment of MPM. (J Thorac Cardiovasc Surg 2016;151:478-84)

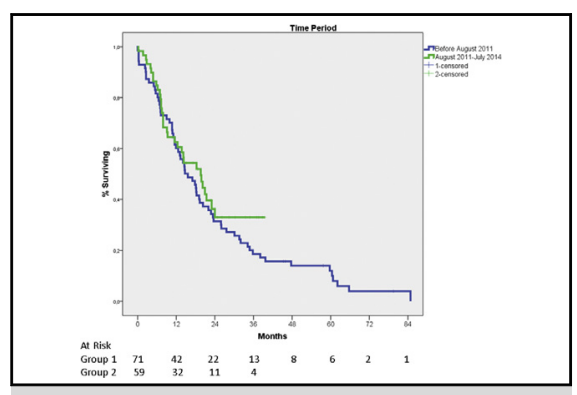

Extrapleural pneumonectomy and pleurectomy and decortication result in the same survival rate in patients with malignant pleural mesothelioma.

\section{Central Message}

Adoption of pleurectomy and decortication as the main surgical approach does not cause survival disadvantage in the treatment of malignant pleural mesothelioma.

\section{Perspective}

Preference of EPP or PD as the main surgical approach does not make a difference in terms of overall survival in patients with MPM. With the growing body of evidence showing relatively similar survival rates with any of the surgical strategies adopted, randomized studies are needed to compare surgical procedures (VATS PD vs EPD and partial PD vs EPD) in the treatment of MPM.

See Editorial Commentary page 485.

See Editorials page 307 and 310.

\footnotetext{
From the ${ }^{\mathrm{a}}$ Department of Thoracic Surgery and ${ }^{\mathrm{d}}$ Division of Medical Oncology, Department of Internal Medicine, Marmara University Faculty of Medicine, Istanbul, Turkey; 'bung and Pleural Cancers Research and Clinical Center, Osmangazi University Faculty of Medicine, Eskisehir, Turkey; and ${ }^{\mathrm{c}}$ Department of Radiation Oncology, Medipol University, Istanbul, Turkey.

Received for publication May 19, 2015; revisions received Sept 3, 2015; accepted for publication Sept 28, 2015; available ahead of print Nov 21, 2015.

Address for reprints: Hasan Fevzi Batirel, MD, PhD, Department of Thoracic Surgery, Marmara University Hospital, 7 Kat, Gogus Cerrahisi Fevzi Cakmak Mah, Mimar Sinan Cad, No. 41, 34899, Ust Kaynarca, Pendik, Istanbul, Turkey (E-mail: hbatirel@marmara.edu.tr).

$0022-5223 / \$ 36.00$

Copyright (c) 2016 by The American Association for Thoracic Surgery

http://dx.doi.org/10.1016/j.jtcvs.2015.09.121
}

Malignant pleural mesothelioma (MPM) is a disease with poor prognosis, mainly due to the rapid progression of the tumor and frequent locoregional failure of treatment strategies.

Scanning this QR code will take you to the article title page. 


\section{Abbreviations and Acronyms \\ $\mathrm{CT}=$ computed tomography \\ $\mathrm{EPD}=$ extended pleurectomy and decortication \\ $\mathrm{EPP}=$ extrapleural pneumonectomy \\ MARS $=$ Mesothelioma and Radical Surgery \\ MCR = macroscopic complete resection \\ MPM = malignant pleural mesothelioma \\ $\mathrm{PD}=$ pleurectomy and decortication}

Several perioperative techniques and strategies were adopted to improve survival in patients with MPM. Multimodality approaches, including surgery, chemotherapy, and radiotherapy in various orders, are shown to improve survival with most series reporting median survivals between 17 and 35 months and 5-year survival of $15 \%$ to $20 \% .^{1-5}$ In 2 recent studies that include more than 500 patients, median survival following extrapleural pneumonectomy (EPP) was 18 months with $15 \%$ 5-year survival rates. ${ }^{1,5}$

Debate about the technique of MPM surgery has lasted for more than 2 decades, with proponents of lung-sacrificing surgery-namely EPP, which includes removal of the ipsilateral lung, diaphragm, and occasionally pericardium and the lung-sparing option of pleurectomydecortication (PD), which includes removal of ipsilateral pleura. Although this debate is ongoing, following the publication of several retrospective comparative series and a consensus statement about surgical principles, macroscopic tumor resection regardless of the surgical technique has become the widely accepted approach. ${ }^{7}$

We have been proponents of EPP as the main surgical technique in the treatment of MPM for about a decade and decided to adopt a lung-sparing approach following a growing body of evidence showing similar survival rates with a lung-sparing surgical technique. ${ }^{3,8}$ The Mesothelioma and Radical Surgery (MARS) trial, which was an underpowered feasibility study with strong anti-EPP conclusions, attracted considerable interest from many clinicians around the world and changed legal consequences in some countries. ${ }^{8}$

We analyzed our single-institution experience in the surgical and multimodality treatment of patients with MPM, comparing periods before and after changing our surgical technique.

\section{METHODS}

One hundred thirty patients were evaluated for multi- or trimodality treatment with histologically proven MPM and underwent surgery in Marmara University Hospital during 2003-2014. The study was approved by the Ethical Council of Marmara University Faculty of Medicine.

All patients with radiologically resectable MPM and no bulky mediastinal or extrapleural lymph node metastasis were evaluated for trimodality treatment. Patients underwent thoracoabdominal computed tomography (CT) scan, positron emission tomography (PET)-CT, laboratory and pulmonary function tests, and cardiac evaluation.
TABLE 1. Demographic, perioperative, and survival data for the cohort $(\mathbf{n}=\mathbf{1 3 0})$

\begin{tabular}{|c|c|}
\hline Data & Result \\
\hline Median age, y & $55.7(26-80)$ \\
\hline \multicolumn{2}{|l|}{ Sex } \\
\hline Female & 54 \\
\hline Male & 76 \\
\hline \multicolumn{2}{|l|}{ Comorbidities } \\
\hline Present & $52(40)$ \\
\hline Cardiopulmonary & 33 \\
\hline Diabetes & 6 \\
\hline Others & 13 \\
\hline None & $78(60)$ \\
\hline \multicolumn{2}{|l|}{ Types of surgical procedures } \\
\hline Extrapleural pneumonectomy & $42(32)$ \\
\hline All pleurectomies* & $66(51)$ \\
\hline Others $\dagger$ & $22(17)$ \\
\hline \multicolumn{2}{|l|}{ Histology } \\
\hline Epithelioid & $97(75)$ \\
\hline Mixed & $26(20)$ \\
\hline Sacromatoid or desmoplastic & $7(5)$ \\
\hline Forced expiratory volume in $1 \mathrm{~s}, \mathrm{~L}$ & $2.05 \pm 0.5$ \\
\hline Postoperative major morbidity & $17(13)$ \\
\hline \multicolumn{2}{|l|}{ Mortality } \\
\hline $30-d$ & $6(4.6)$ \\
\hline $90-d$ & $13(10)$ \\
\hline Length of hospital stay, $d$ & $7.6 \pm 4.1$ \\
\hline \multicolumn{2}{|l|}{ Resection status } \\
\hline 1 & $70(54)$ \\
\hline 2 & $60(46)$ \\
\hline \multicolumn{2}{|l|}{ Surgical T status } \\
\hline $\mathrm{T} 1$ and $\mathrm{T} 2$ & $62(48)$ \\
\hline $\mathrm{T} 3$ and $\mathrm{T} 4$ & $68(52)$ \\
\hline \multicolumn{2}{|l|}{ Pathologic $\mathrm{N}$ status } \\
\hline 0 & $65(50)$ \\
\hline 1 & $1(1)$ \\
\hline 2 & $22(17)$ \\
\hline $\mathrm{X}_{\ddagger}^{\dagger}$ & $42(32)$ \\
\hline Mean follow-up, mo & $19.1 \pm 16.8$ \\
\hline \multicolumn{2}{|l|}{ Sites of recurrence } \\
\hline Locoregional & $69(53)$ \\
\hline Distant & $9(7)$ \\
\hline Locoregional and distant & $19(15)$ \\
\hline Median overall survival, $\mathrm{n}$ & 17.8 \\
\hline \multicolumn{2}{|l|}{ Survival rates, $\%$} \\
\hline $2-\mathrm{y}$ & 32 \\
\hline $5-y$ & 14 \\
\hline
\end{tabular}

Data are presented as $\mathrm{n}(\%)$, median (range), or mean \pm standard deviation unless otherwise noted. *Pleurectomy decortication with macroscopic complete resection $(\mathrm{n}=30)$ and partial pleurectomy decortication $(\mathrm{n}=36)$. †Explorative video-assisted thoracoscopic surgery and diagnostic procedures. $¥$ Mediastinal lymph nodes not surgically evaluated.

Mediastinal staging was based on CT findings until 2005 and afterward on fluorine-18-fluorodeoxyglucose PET-CT. If there was any suspicion of mediastinal lymph node involvement, cervical mediastinoscopy was performed. Magnetic resonance imaging was also frequently used in case of suspicion of involvement beyond the pleural envelope.

The treatment strategy before August 2011 was to perform EPP (with ipsilateral diaphragm and/or pericardial resection), adjuvant high-dose 

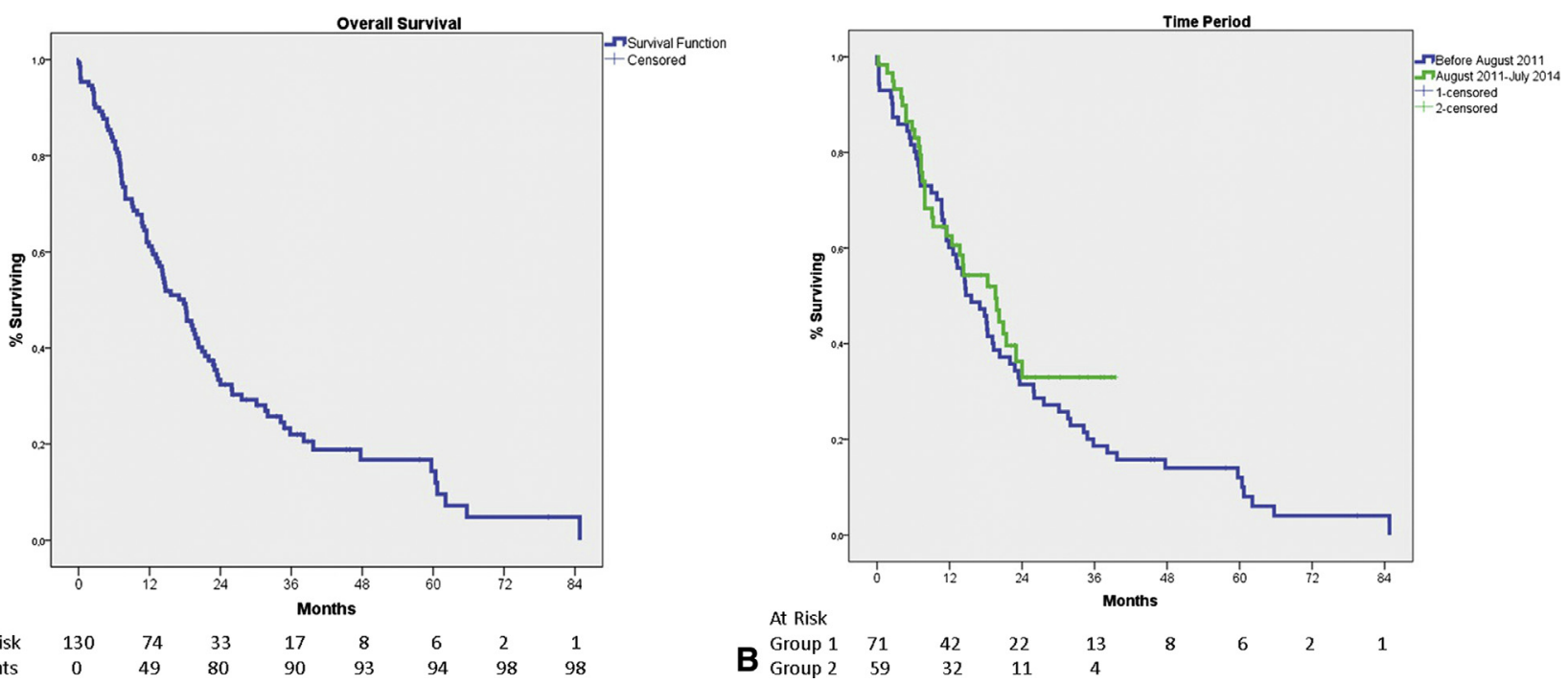

FIGURE 1. A, Survival curve of 130 patients. Overall median survival was 17.8 months (95\% CI, 13.7-21.9) and 2- and 5-year survival rates were $32 \%$ (95\% CI, 28\%-37\%) and 14\% (95\% CI, 10\%-19\%), respectively. B, Survival comparison between the 2 time periods (group 1 [March 2003-July 2011] vs group 2 [August 2011-June 2014]). Overall median survivals and 2-year survival rates were 15.6 months (95\% CI, 10.7-20.5) and 32\% (95\% CI, 26\%-37\%) versus 19.6 months (95\% C,I $12.7-26.5)$ and 33\% (95\% CI, 26\%-40\%), respectively $(P=.34)$.

hemithoracic irradiation either with 3-dimensional conformal or intensitymodulated radiation therapy and chemotherapy. ${ }^{9}$ After August 2011, our treatment intent was to perform extended pleurectomy and decortication (EPD), prophylactic irradiation to the incisions, and the same adjuvant chemotherapy.

Macroscopic complete resection (MCR) of the tumor was our surgical aim and if this was achieved without removing diaphragm and/or pericardium, this was accepted as EPD. Resections with curative intent were accepted as EPP or PD with MCR. ${ }^{10}$ Other surgical techniques were accepted as palliative. If gross tumor was left behind the method was accepted as partial PD. In patients with EPD, adjuvant chemotherapy and only prophylactic radiation was applied and hemithoracic irradiation was reserved for subsequent locoregional failure. The strategy of delaying hemithoracic irradiation for patients with MCR was mainly due to the possibility of achieving local control with chemotherapy while avoiding the potential lung toxicities that might come up with radiation. However, in patients in whom macroscopic tumor was left behind, adjuvant chemotherapy and hemithoracic irradiation to the gross tumor sites was performed. As adjuvant chemotherapy, patients received a total of 4 to 6 courses of chemotherapy. Platin-based combination chemotherapy was administered. Until 2005, gemcitabine was the second agent in the combination, after 2005 pemetrexed was used. A regimen of $75 \mathrm{mg} / \mathrm{m}^{2}$ cisplatin day 1 or area under the curve 5 carboplatin on day $1,1000 \mathrm{mg} / \mathrm{m}^{2}$ gemcitabine days 1 and 8 or $500 \mathrm{mg} / \mathrm{m}^{2}$ pemetrexed day 1 were given every 3 weeks.

The data were collected retrospectively from a prospective database. Demographic criteria (age, gender, and comorbidities), types of surgical procedures, histology, pulmonary function tests and postoperative morbidity and mortality (30 and 90 day), length of hospital stay, pathologic stage, site of recurrence, and survival were recorded. Major morbidities were accepted as postoperative bleeding necessitating exploration, respiratory insufficiency, bronchopleural fistula, pulmonary emboli, chylothorax, and multiorgan failure.

Kaplan-Meier survival analysis was performed. Factors affecting survival (eg, gender, side of resection, histology [epithelioid vs nonepithelioid], type of surgery [EPP vs pleurectomies vs diagnostic interventions], completeness of resection [R1 vs R2], $\mathrm{T}$ status [T1+T2 vs T3+T4] and N status [N0, N2, or not assessed], and type of treatment [only surgery, bimodality, or trimodality]) in the whole cohort were evaluated with uni- and multivariate analysis using IBM SPSS 20.0 software (IBM SPSS Inc, Armonk, NY).

Bimodality treatment was accepted as surgery and adjuvant chemotherapy. Palliative incisional radiation was not accepted as a treatment modality. Trimodality treatment was accepted as surgery, chemotherapy, and irradiation. Irradiation was accepted as a modality in the trimodality approach if it was high-dose hemithoracic irradiation either with three-dimensional conformal or intensity-modulated radiation therapy technique following PD.

\section{Formation of Groups and Comparisons}

The patients were additionally evaluated in 2 groups. Group 1 included patients between March 2003 and July 2011 and group 2 included patients between August 2011 and July 2014. The 2 groups were compared for demographic data, types of surgical procedures, histology, pulmonary function tests, postoperative major morbidity and mortality, length of hospital stay, pathologic stage, sites and frequency of recurrence, and survival.

Statistical analysis was performed using Kaplan-Meier survival analysis, $\log$ rank, Student $t$ test, and $\chi^{2}$ test.

\section{RESULTS}

One hundred thirty patients ( 75 men; median age, 55.7 years [range, 26-80 years]) underwent surgical intervention for MPM during this period. Detailed demographic, pre-, and postsurgical data of the whole cohort are shown in Table 1. History of environmental and occupational asbestos exposure was present in 75 and 14 patients, respectively.

Overall median survival was 17.8 months and 2- and 5-year survivals were $32 \%$ and $14 \%$, respectively (Figure 1, A). Ninety-seven patients $(75 \%)$ had epithelioid histology and 70 patients $(54 \%)$ had surgery that resulted in complete macroscopic tumor clearance.

Univariate analysis showed that histology (Figure 2, A), pathologic N0 status (Figure 2, B), and trimodality treatment (Figure 2, $C$ ) were significantly associated with better survival $(P=.039, P=.012$, and $P<.001$, respectively $)$. 

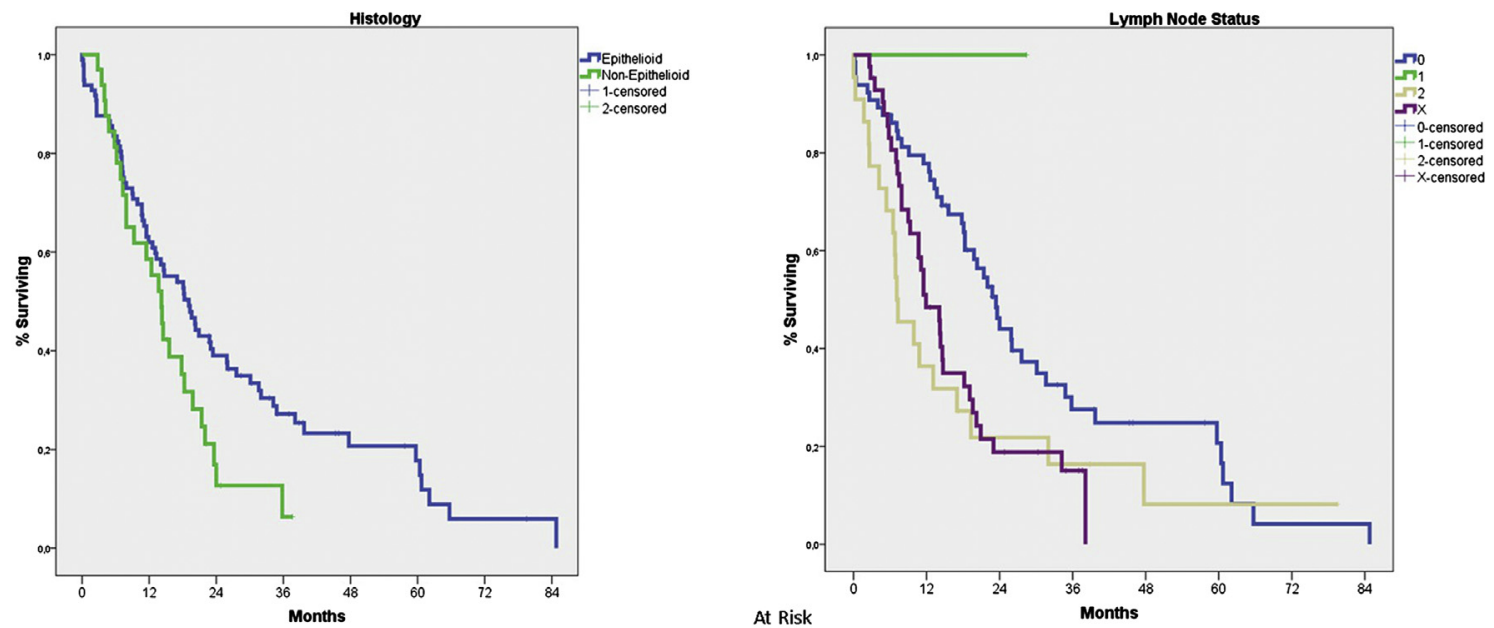

At Risk

$\begin{array}{lllllllll}\text { Epithelioid } & 97 & 56 & 29 & 16 & 8 & 6 & 2 & 1\end{array}$
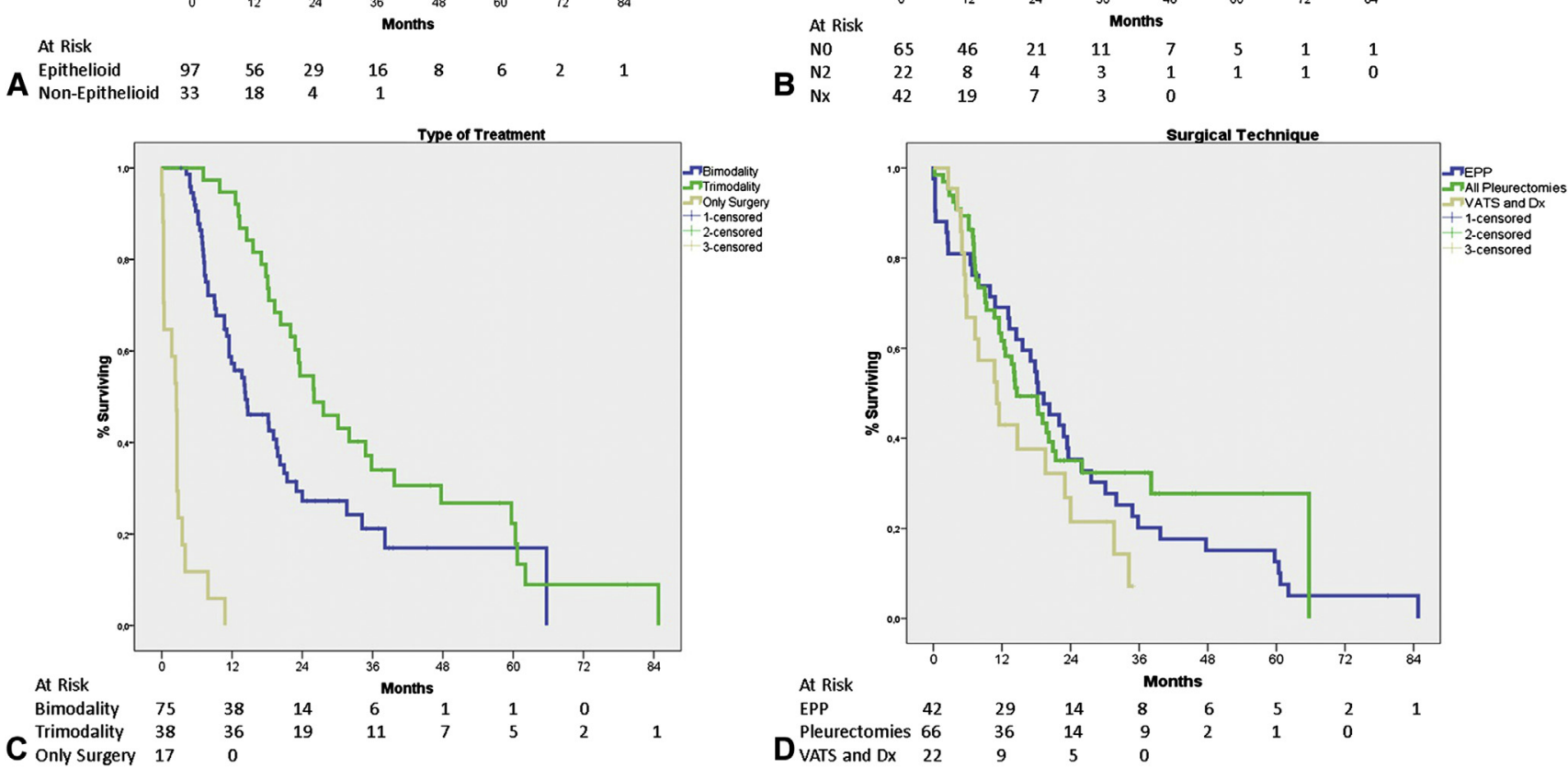

FIGURE 2. A, Survival comparison of patients with epithelioid and nonepithelioid histology. Median survival and 2-year survival rates were 19.1 months $(95 \% \mathrm{CI}, 13.8-24.4)$ and $39 \%(95 \% \mathrm{CI}, 34 \%-44 \%)$ versus 14.2 months $(95 \% \mathrm{CI}, 11.4-17)$ and $17 \%(95 \% \mathrm{CI}, 10 \%-24 \%)$, respectively $(P=.039)$. B, Survival comparison of patients with no lymph node metastasis (N0), extrapleural lymph node metastasis (N2), and unknown lymph node status (Nx). Median survival and 2-year survival rates were 23.4 months (95\% CI, 19.5-27.3) and 46\% (95\% CI, 39\%-53\%) versus 7.1 months (95\% CI, $3.5-10.7)$ and $22 \%(95 \%$ CI, $13 \%-31 \%$ ) versus 11.9 months (95\% CI, 8.2-15.6) and 19\% (95\% CI, 13\%-25\%), respectively $(P=.012)$. C, Survival comparison of patients with only surgery, bimodality treatment, and trimodality treatment. Median survival and 2-year survival rates were 2.5 months (95\% CI, 1.8-3.2) and $0 \%$ versus 14.3 months (95\% CI, 8.3-20.3) and 29\% (95\% CI, $23 \%-35 \%$ ) versus 26 months (95\% CI, $18-34)$ and $55 \%$ (95\% CI, 46\%-63\%), respectively $(P<.001)$. D, Survival comparison of patients who underwent extrapleural pneumonectomy, pleurectomy, and diagnostic interventions (eg, video-assisted thoracoscopic surgery). Median survival and 2-year survival rates were 18.3 months (95\% CI, 13-23.6) and 35\% (95\% CI, 28\%-43\%) versus 14.6 months (95\% CI, 9.4-19.8) and 35\% (95\% CI, 29\%-42\%) versus 11.1 months (95\% CI, 5.7-16.5) and 22\% (95\% $\mathrm{CI}, 12 \%-31 \%)$, respectively $(P=.14)$. EPP, Extrapleural pneumonectomy; VATS, video-assisted thoracoscopic surgery; $D x$, diagnostic interventions.

Gender, resection status, side, type of surgery (EPP vs pleurectomies vs diagnostic interventions), and $\mathrm{T}$ stage (T1 and 2 vs T3 and T4) were not found to be significant ( $P=.6, P=.38, P=.9, P=.14$, and $P=.33$, respectively).

All 3 factors were also significant in multivariate analysis and pathologic N0 status was found to be the most important factor followed by epithelioid histology and trimodality treatment $(P<.001, P=.009$, and $P=.028$, respectively) (Table 2$)$.

\section{Comparison of Time Periods}

Group 1 was compared with group 2 and the results are shown in Table 3 . The types of surgical procedures were different between the 2 groups. Upfront chemotherapy (neoadjuvant or standard regimen) were applied more frequently in group 2 . There were also more nonepithelioid tumors in group 2. Complete macroscopic tumor clearance was achieved in $65 \%$ of group 1 , whereas only in $40 \%$ of 
TABLE 2. Multivariate analysis of significant prognostic variables $(\mathrm{N}=130)$

\begin{tabular}{lcccr}
\hline \multicolumn{1}{c}{ Variable } & Hazard & $\begin{array}{c}\text { Confidence } \\
\text { ratio }\end{array}$ & \multicolumn{1}{c}{$\boldsymbol{P}$} \\
interval & value \\
\hline Extrapleural lymph node metastasis & 20 & 1.39 & $1.18-1.64$ & $<.001$ \\
Non-epithelioid histology & 33 & 1.84 & $1.16-2.9$ & .009 \\
Not receiving trimodality treatment & 86 & 1.6 & $1.05-2.42$ & .028 \\
\hline
\end{tabular}

group $2(P=.006)$. Mean follow-up was longer in group 1 $(P<.001)$. Major morbidity was more frequent in group 1 , mainly due to the adoption of EPP as the main surgical technique. All other parameters were similar between the 2 time periods. Survival rates were similar between the 2 time periods (median survival was 15.6 and 19.6 months; 2-year survival rates were $32 \%$ and $33 \%$, respectively; $P=.33$ ) (Figure 1, B).

\section{DISCUSSION}

Surgical technique and treatment strategies for MPM are still under discussion. This is mainly due to inadequacy of current clinical and pathologic staging system, significant prognostic difference between histologic subtypes, and use of various surgical techniques that are still under investigation at many centers that specialize in MPM surgery. However, over the past 2 decades we have made significant progress in standardizing surgical technique and nomenclature, multimodality treatment, locoregional control, and thus overall survival.

EPP was popularized following the article published by Sugarbaker and colleagues in 1999. ${ }^{1}$ In that study, survival was very good in a subgroup of 31 patients (out of 183) who had epithelioid MPM with pathologic stage N0 and underwent MCR. ${ }^{1}$ Five-year survival rate was $46 \%$ and median survival was 51 months in this subgroup.

The benefit of EPP in terms of survival extension was first questioned by Flores and colleagues ${ }^{11}$ in 2008 and retrospective analysis of 663 patients from a specialized center showed that EPP had no benefit. It even concluded that EPP could be harmful when compared with PD with a hazard ratio of 1.4. In a highly selected group of patients who underwent PD, Lang-Lazdunski and colleagues ${ }^{12}$ and Bölükbas and colleagues ${ }^{13}$ both showed median survivals over 30 months. Bölükbas and colleagues ${ }^{14}$ recently reported a median survival of 22 months and a 5-year survival rate of $28 \%$ in patients with stage III disease who underwent EPD followed by chemoradiation. Whereas other researchers ${ }^{15}$ showed a median survival of 16 months in the same patient group who underwent $\mathrm{PD}$, which reflects significant differences in patient selection.

Lazdunski and colleagues ${ }^{16}$ reported results of 102 patients who underwent intrapleural povidone-iodine lavage in 2015. Their survival data were better, with a median survival of 32 months and a 5-year survival rate
TABLE 3. Comparison of variables before (group 1: March 2003 to July 2011) and after August 2011 (group 2: August 2011 to July 2014)

\begin{tabular}{|c|c|c|c|}
\hline Variable & $\begin{array}{l}\text { Group 1 } \\
(n=71)\end{array}$ & $\begin{array}{l}\text { Group 2 } \\
(\mathbf{n}=59)\end{array}$ & $\begin{array}{c}P \\
\text { value }\end{array}$ \\
\hline Median age, $\mathrm{y}$ & $54.8(41-75)$ & $57(26-80)$ & .45 \\
\hline Gender (female/male) & $29 / 42$ & $25 / 34$ & .99 \\
\hline Side (right/left) & $46 / 25$ & $33 / 26$ & .3 \\
\hline Type of surgical procedures & & & $<.001$ \\
\hline Extrapleural pneumonectomy & $40(56)$ & $2(3)$ & \\
\hline All pleurectomies* & $20(28)$ & $46(78)$ & \\
\hline Others $\dagger$ & $11(16)$ & $11(19)$ & \\
\hline Preoperative chemotherapy & $7(10)$ & $22(37)$ & $<.001$ \\
\hline Histology & & & $<.001$ \\
\hline Epithelioid & $62(87)$ & $35(59)$ & \\
\hline Mixed & 7 & 19 & \\
\hline Sacromatoid or desmoplastic & 2 & 5 & \\
\hline Resection status (R1/2) & 25 & & .006 \\
\hline 1 & $46(65)$ & $24(41)$ & \\
\hline 2 & 25 & 35 & \\
\hline Forced expiratory volume in $1 \mathrm{~s}, \mathrm{~L}$ & $2.64 \pm 0.7$ & $2.83 \pm 0.67$ & .11 \\
\hline Major morbidity & $14(20)$ & $3(5)$ & .014 \\
\hline Mortality, d & & & .15 \\
\hline 30 & $5(7)$ & $1(2)$ & \\
\hline 90 & $9(13)$ & $4(7)$ & \\
\hline Length of hospital stay, d & $8.2 \pm 4.1$ & $7 \pm 4$ & .1 \\
\hline Surgical T status & & & .45 \\
\hline 1 and 2 & 36 & 26 & \\
\hline 3 and 4 & 35 & 33 & \\
\hline
\end{tabular}

$$
0
$$

1

2

$\mathrm{X}^{\dagger}$

$\begin{array}{ccc}34(48) & 31(53) & \\ 0 & 1 & \\ 15(21) & 7(12) & \\ 22 & 20 & \\ 22.5 \pm 20.6 & 16.4 \pm 10.9 & <.001 \\ 60(85) & 54(92) & .73\end{array}$

Adjuvant treatment

(chemotherapy or

chemoradiation)

Sites of recurrence

Locoregional

Distant

Locoregional and distant

Median overall survival, mo

2-y survival rate $(\%)$

Values are presented as median (range), $\mathrm{n}, \mathrm{n}(\%)$, or mean \pm standard deviation. *Including pleurectomy-decortication with macroscopic complete resection + partial pleurectomy-decortication. †Exploratory video-assisted thoracoscopic surgery and diagnostic procedures. ‡Mediastinal lymph nodes not surgically evaluated.

of $23 \%$. However in those patients pathologic N0 status was found in 67 patients $(68 \%)$ and MCR was achieved in 57 patients $(58 \%)$. In our series pathologic N0 status was present in 65 patients $(50 \%)$ and macroscopic complete resection was achieved in 70 patients $(54 \%)$. Adding to the body of evidence, a recent meta-analysis comparing EPP and PD showed that survival rates were similar between the 2 techniques and there was no benefit for EPP in the surgical treatment of MPM. ${ }^{3}$ In our study, although the patients who completed trimodality treatment 
TABLE 4. Prognostic factors in patients with malignant pleural mesothelioma in major surgical series

\begin{tabular}{|c|c|c|c|c|}
\hline First author, $\mathbf{y}$ & $\mathbf{N}$ & Type of treatment & Median survival, mo & Multivariate analysis \\
\hline Lazdunski, $2015^{16}$ & 102 & $\mathrm{PD}+\mathrm{IOI}+\mathrm{MM}$ & 32 & Epithelioid histology and macroscopic complete resection \\
\hline Sugarbaker, $2014 * 6$ & 529 & $\mathrm{EPP}+\mathrm{MM}$ & 18 & Female gender, age, N0 \\
\hline Spaggiari, $2014^{5}$ & 518 & $\mathrm{EPP}+\mathrm{MM}$ & 18 & Female gender, epithelioid histology, trimodality treatment \\
\hline Gomez, $2013^{23}$ & 136 & $\mathrm{EPP}+\mathrm{IMRT}$ & 14.7 & $\begin{array}{l}\text { Epithelioid histology, N0-N1, low pretreatment forced } \\
\text { expiratory volume in } 1 \mathrm{~s}\end{array}$ \\
\hline Bolukbas, $2013^{*}, \dagger^{14}$ & 78 & $\mathrm{PD}+\mathrm{MM}$ & 32 & Tumor inoculation at previous resection sites \\
\hline Flores, $2008^{11}$ & 663 & $\begin{array}{l}\operatorname{EPP}(\mathrm{n}=385) \\
\quad \operatorname{PD}(\mathrm{n}=278)+\mathrm{MM}\end{array}$ & 17 & $\begin{array}{l}\text { Age, female gender, } \mathrm{EPP}_{\ddagger}^{\dagger} \text {, epithelioid histology, stage III/IV, } \\
\text { multimodality treatment }\end{array}$ \\
\hline Batirel, current study & 130 & $\begin{array}{l}\operatorname{EPP}(\mathrm{n}=42)+ \\
\quad \operatorname{PD}(\mathrm{n}=71)+\mathrm{MM}\end{array}$ & 17.8 & N0, epithelioid histology, trimodality treatment \\
\hline
\end{tabular}

$P D$, Extended pleurectomy-decortication; $I O I$, intraoperative iodine lavage; $M M$, multimodality treatment; $E P P$, extrapleural pneumonectomy; IMRT, intensity-modulated radiation treatment. *Only epithelioid histology. †Patients with clinical stage III disease only. $\ddagger$ Poor prognostic factor.

(surgery [30 EPP and 8 PD patients and 34 patients were in group 1] + adjuvant chemoradiation) had a median survival of 26 months, overall survival was not different between the 2 periods. Only 29\% (38 out of 130) of the patients completed trimodality treatment, which shows a significant selection bias in this subgroup. However, longest survival in our series was achieved by application of EPP and adjuvant chemoradiation. Thus similar survival rates between 2 periods should not preclude patients from lung-sacrificing surgery in appropriate clinical situations.

The main argument against EPP was that it had higher morbidity and mortality compared to PD and did not provide any survival advantage. This was supported in a recent review of the Society of Thoracic Surgeons database. ${ }^{17}$ Pulmonary morbidity and mortality were found to be increased following EPP when compared with PD (adult respiratory distress syndrome, $8.5 \%$ vs $0.8 \%$ and $10.2 \%$ vs $3.1 \%$, respectively). However that study was performed in 48 centers and a total of 225 patients were collected over 2 years. ${ }^{17}$ In our series, we also had significantly higher morbidity and a slightly higher 30- and 90-day mortality in group 1, when EPP was our preferred surgical technique. But this was during the initial 5 years of our practice. In experienced centers with high patient volume (ie, $>10 /$ year), mortality following EPP is usually $<5 \%$. ${ }^{1,4,9}$

Our group changed its surgical strategy for MPM in August 2011, following the data from several series showing similar survival rates with a non-EPP approach. ${ }^{711-16,18}$ In the MARS trial the survival rate in the non-EPP arm was 19.5 months, which could be reached with EPP and multimodality treatment in most series. The non-EPP arm received mainly chemotherapy, palliative radiation, and surgery, but the report does not provide any details regarding the surgical procedures in this group. ${ }^{8}$ Randomization was after 3 cycles of neoadjuvant treatment in the MARS trial and involved patients with potentially resectable MPM. Thus chemotherapy may be an important factor for achievement of better survival rate. Proponents of nonsurgical treatment of MPM showed that with only chemotherapy (eg, cisplatin, doxorubicin, and gemcitabine), they could achieve a median survival of 22 months and 5-year survival rate of $10 \%$ in patients with good performance status, T1 or T2 tumors, epithelioid MPM, and patients younger than age 70 years. ${ }^{19}$ Recently in a multicenter Italian study ${ }^{20}$ in the favorable subgroup of patients with epithelioid histology aged younger than 70 years and who received EPP, PD, and only chemotherapy median survivals were 20.9, 24.6, and 18.6 months, respectively $(P=.596)$. We found a 20.9 -month median survival in patients who underwent partial PD and chemotherapy $(\mathrm{n}=22)$ during the latter period. The MesoVATS trial also showed an equivalent survival between video-assisted thoracoscopic surgery PD and talc pleurodesis in MPM patients with survival rates of $52 \%$ and $57 \%$, respectively, at 1 year. ${ }^{21}$ However in an earlier review of published series, ${ }^{22}$ it was shown that addition of surgery to multimodality treatment protocols for MPM patients led to a survival extension of up to 9 months.

Table 4 shows significant prognostic factors using multivariate analysis in various surgical series. ${ }^{1,5,11,14,16,23}$ In all series, epithelioid histology was the most significant prognostic factor, followed by $\mathrm{N}$ stage status, use of multimodality treatment, and MCR. Most of the series did not find surgical technique as a prognostic factor, other than 1 group,$^{11}$ which showed EPP as a poor prognostic factor.

We had more nonepithelioid MPM patients, more frequent use of upfront chemotherapy, and fewer patients undergoing MCR in the latter period. The abundance of nonepithelioid patients is possibly due to the more frequent use of neoadjuvant treatment, which is more effective on the epithelioid cell type. The relatively lower frequency of patients with $\mathrm{N} 2$ status in the latter group is secondary to avoidance of straightforward surgery for patients with clinical T1 to T3 N0 to N2 disease, which was a common protocol we applied during the former period. ${ }^{9}$ Analysis of survival from the date of surgery in many series leads to bias, because some patients receive upfront treatment for 3 to 6 months after diagnosis. 
Our study has several weaknesses. It is a singleinstitution study. The experience of the team increased over the years, especially in the refinement of intraoperative surgical technique and multimodality treatment, which leads to a selection bias. Also there are patients who received palliative exploratory surgical interventions. Despite these weaknesses, overall survival in our patient cohort was identical to that found in 2 EPP series with large patient populations. ${ }^{1,5}$

\section{CONCLUSIONS}

Preference of EPP or PD as the main approach does not make a difference in terms of overall survival in patients with MPM. With the growing body of evidence showing relatively similar survival rates with any of the surgical strategies adopted, randomized studies are needed to compare various greater and lesser surgical procedures (eg, EPD vs video-assisted thoracoscopic surgery PD and EPD vs partial PD) with each other or even with no surgical intervention in the context of multimodality treatment. ${ }^{24,25}$ Our study provides further data to support such a research effort.

\section{Conflict of Interest Statement}

Authors have nothing to disclose with regard to commercial support.

The authors thank Nural Bekiroglu, PhD, professor of biostatistics, for assisting with the statistical analysis. The preparation of this manuscript was supported by Marmara University Scientific Research and Projects Commission (Marmara-BAPKO).

\section{References}

1. Sugarbaker DJ, Flores RM, Jaklitsch MT, Richards WG, Strauss GM, Corson JM, et al. Resection margins, extrapleural nodal status, and cell type determine postoperative long-term survival in trimodality therapy of malignant pleural mesothelioma: results in 183 patients. J Thorac Cardiovasc Surg. 1999;117:54-65.

2. Opitz I. Management of malignant pleural mesothelioma: the European experience. J Thorac Dis. 2014;6(Suppl 2):S238-52.

3. Cao C, Tian D, Park J, Allan J, Pataky KA, Yan TD. A systematic review and meta-analysis of surgical treatments for malignant pleural mesothelioma. Lung Cancer. 2014;83:240-5.

4. Lauk O, Hoda MA, de Perrot M, Friess M, Klikovits T, Klepetko W, et al. Extrapleural pneumonectomy after induction chemotherapy: perioperative outcome in 251 mesothelioma patients from three high-volume institutions. Ann Thorac Surg. 2014;98:1748-54.

5. Spaggiari L, Marulli G, Bovolato P, Alloisio M, Pagan V, Oliaro A, et al. Extrapleural pneumonectomy for malignant mesothelioma: an Italian multicenter retrospective study. Ann Thorac Surg. 2014;97:1859-65.

6. Sugarbaker DJ, Richards WG, Bueno R. Extrapleural pneumonectomy in the treatment of epithelioid malignant pleural mesothelioma: novel prognostic implications of combined N1 and N2 nodal involvement based on experience in 529 patients. Ann Surg. 2014;260:577-82.

7. Rusch V, Baldini EH, Bueno R, De Perrot M, Flores R, Hasegawa S, et al. The role of surgical cytoreduction in the treatment of malignant pleural mesothelioma: meeting summary of the International Mesothelioma Interest Group Congress, September 11-14, 2012, Boston, Mass. J Thorac Cardiovasc Surg. 2013;145:909-10.

8. Treasure T, Lang-Lazdunski L, Waller D, Bliss JM, Tan C, Entwisle J, et al. Extra-pleural pneumonectomy versus no extra-pleural pneumonectomy for patients with malignant pleural mesothelioma: clinical outcomes of the Mesothelioma and Radical Surgery (MARS) randomised feasibility study. Lancet Oncol. 2011;12:763-72.

9. Batirel HF, Metintas M, Caglar HB, Yildizeli B, Lacin T, Bostanci K, et al. Trimodality treatment of malignant pleural mesothelioma. J Thorac Oncol. 2008;3:499-504.

10. Rice D, Rusch V, Pass H, Asamura H, Nakano T, Edwards J, et al. Recommendations for uniform definitions of surgical techniques for malignant pleural mesothelioma: a consensus report of the International Association for the Study of Lung Cancer International Staging Committee and the International Mesothelioma Interest Group. J Thorac Oncol. 2011;6: 1304-12.

11. Flores RM, Pass HI, Seshan VE, Dycoco J, Zakowski M, Carbone M, et al. Extrapleural pneumonectomy versus pleurectomy-decortication in the surgical management of malignant pleural mesothelioma: results in 663 patients. $J$ Thorac Cardiovasc Surg. 2008;135:620-6.

12. Lang-Lazdunski L, Bille A, Lal R, Cane P, McLean E, Landau D, et al. Pleurectomy/decortication is superior to extrapleural pneumonectomy in the multimodality management of patients with malignant pleural mesothelioma. $J$ Thorac Oncol. 2012;7:737-43.

13. Bölükbas S, Manegold C, Eberlein M, Bergmann T, Fisseler-Eckhoff A, Schirren J. Survival after trimodality therapy for malignant pleural mesothelioma: radical pleurectomy, chemotherapy with cisplatin/pemetrexed and radiotherapy. Lung Cancer. 2011;71:75-81.

14. Bölükbas S, Eberlein M, Kudelin N, Demes M, Stallmann S, Fisseler-Eckhoff A, et al. Factors predicting poor survival after lung-sparing radical pleurectomy of IMIG stage III malignant pleural mesothelioma. Eur J Cardiothorac Surg. 2013;44:119-23.

15. Nakas A, von Meyenfeldt E, Lau K, Muller S, Waller D. Long-term survival after lung-sparing total pleurectomy for locally advanced (International Mesothelioma Interest Group Stage T3-T4) non-sarcomatoid malignant pleural mesothelioma. Eur J Cardiothorac Surg. 2012;41:1031-6.

16. Lang-Lazdunski L, Bille A, Papa S, Marshall S, Lal R, Galeone C, et al. Pleurectomy/decortication, hyperthermic pleural lavage with povidone-iodine, prophylactic radiotherapy, and systemic chemotherapy in patients with malignant pleural mesothelioma: a 10-year experience. J Thorac Cardiovasc Surg. 2015;149:558-66.

17. Burt BM, Cameron RB, Mollberg NM, Kosinski AS, Schipper PH, Shrager JB, et al. Malignant pleural mesothelioma and the Society of Thoracic Surgeons Database: an analysis of surgical morbidity and mortality. J Thorac Cardiovasc Surg. 2014;148:30-5.

18. Weder W, Stahel RA, Baas P, Dafni U, de Perrot M, McCaughan BC, et al. The MARS feasibility trial: conclusions not supported by data. Lancet Oncol. 2011; 12:1093-5

19. Hillerdal G, Sorensen JB, Sundström S, Riska H, Vikstrom A, Hjerpe A. Treatment of malignant pleural mesothelioma with carboplatin, liposomized doxorubicin, and gemcitabine: a phase II study. J Thorac Oncol. 2008;3:1325-31.

20. Bovolato P, Casadio C, Billè A, Ardissone F, Santambrogio L, Ratto GB, et al. Does surgery improve survival of patients with malignant pleural mesothelioma?: a multicenter retrospective analysis of 1365 consecutive patients. J Thorac Oncol. 2014;9:390-6.

21. Rintoul RC, Ritchie AJ, Edwards JG, Waller DA, Coonar AS, Bennett M, et al. Efficacy and cost of video-assisted thoracoscopic partial pleurectomy versus talc pleurodesis in patients with malignant pleural mesothelioma (MesoVATS): an open-label, randomised, controlled trial. Lancet. 2014;384:1118-27.

22. Utley M, Fiorentino F, Treasure T. Obtaining an upper estimate of the survival benefit associated with surgery for mesothelioma. Eur J Cardiothorac Surg. 2010;38:241-4.

23. Gomez DR, Hong DS, Allen PK, Welsh JS, Mehran RJ, Tsao AS, et al. Patterns of failure, toxicity, and survival after extrapleural pneumonectomy and hemithoracic intensity-modulated radiation therapy for malignant pleural mesothelioma. J Thorac Oncol. 2013;8:238-45.

24. Hiddinga BI, van Meerbeeck JP. Surgery in mesothelioma - where do we go after MARS? J Thorac Oncol. 2013;8:525-9.

25. Datta A, Smith R, Fiorentino F, Treasure T. Surgery in the treatment of malignant pleural mesothelioma: recruitment into trials should be the default position. Thorax. 2014;69:194-7.

Key Words: malignant pleural mesothelioma, extrapleural pneumonectomy, pleurectomy, decortication 